\title{
METODOLOGIA PARA AVALIAR AS PROPRIEDADES DE COQUEIFICAÇÃO DO CARVÃO - BOX TEST*
}

José Eustáquio da Silva ${ }^{1}$ Amilton Ferreira de Oliveira ${ }^{2}$

\section{Resumo}

Este trabalho mostra a versatilidade e praticidade do uso da metodologia denominada "Método e Aparelho para Avaliar as Propriedades de Coqueificação do Carvão", metodologia esta desenvolvida e patenteada pelo corpo técnico da SunCoke Energy. Esta técnica tem possibilitado o desenvolvimento de novas misturas de carvões totalmente alinhadas com os dois grandes pilares da Siderurgia mundial: misturas e coque com baixo custo e qualidade adequada. A fidelização com todas as particularidades do processo real de coqueificação faz desta metodologia uma poderosa ferramenta para tomada de decisão na definição de novos blends, como também para a caracterização de carvões dos quais ainda não se conhece seu potencial para produzir um coque de boa qualidade. Diferentemente das tecnologias similares existentes, o "Box Test" da SunCoke Energy tem robustez suficiente para ser reutilizado para até quatro enfornamentos e é capaz de produzir massa suficiente de coque para que sejam realizadas todas as análises para uma perfeita caracterização do coque.

Palavras-chave: Caracterização; Carvões de coqueria; Metodologia

\section{METHODOLOGY FOR TESTING COAL COKING PROPERTIES - BOX TESTING}

\begin{abstract}
This paper shows the versatility and practicality the methodology called "Method and Apparatus for Evaluating the coking properties of the coal," this methodology developed and patented by SunCoke Energy. This technique has enabled the development of new coal blends completely aligned with the two great pillars of the steel industry: coal blends and coke with low cost and adequate quality. The fidelity with all the features of the coking process, makes this methodology a powerful tool to make decision in order to choose a new coal blend, as well as to characterize coals whose potential to produce good coke is not known yet. Unlike similar existing technologies, "The SunCoke Box Test" has sufficient strength to be reused for up to four times and enough coke mass to carry out all necessary analyzes for a complete coke characterization.
\end{abstract}

Keywords: Characterization; Coals; Methodology

1 Engenharia de Produção, Coordenador de Qualidade, SunCoke Energy Brasil, Serra-ES, Brasil.

2 Engenharia Metalúrgica, Consultor de Qualidade, SunCoke Energy Brasil, Serra-ES, Brasil. 


\section{INTRODUÇÃO}

A metodologia de utilização de Box Test para caracterização de carvões em coquerias heat recovery teve a patente concedida pelo INPI. Trata-se de um eficiente e assertivo método para caracterização de carvões e mistura, visto que o dispositivo utilizado foi especialmente desenvolvido para simular as mesmas condições operacionais em que as misturas são submetidas, eliminando assim as inerentes limitações dos tradicionais fornos-pilotos, principalmente custo, controle térmico e tamanho da amostra. A caixa utilizada preserva algumas referências geométricas dos fornos da SunCoke Energy, tem capacidade para simular diferentes níveis de densidade da mistura, possui duplo compartimento que permite o teste simultâneo de dois materiais diferentes, como também pode ser reutilizada até quatro vezes. O termo "Box Test" aqui empregado, não se caracteriza apenas com uma caixa de teste, mas sim como uma criteriosa metodologia para caracterização de carvões que engloba as seguintes fases: 1) definição de misturas; 2) elaboração de misturas em laboratório; homogeneização das misturas; 3) britagem seletiva das misturas; 4) controle de umidade e densidade da mistura; 5) controle de abastecimento da caixa; 6) controle térmico durante a coqueificação; 7) resfriamento da caixa; 8) classificação do coque (coque de sole flue e coque de crown) e 9) caracterização completa do coque (análise imediata, análise elementar, granulometria, CRI, CSR e DI).

Neste trabalho serão abordados todo o sequenciamento da aplicação desta metodologia, bem como breves comparações com técnicas similares, além da apresentação dos resultados práticos obtidos na SunCoke Energy após o início do uso desta metodologia, comprovadamente eficaz, para avaliação do potencial de coqueificação de carvões e misturas de carvões.

\section{MATERIAIS E MÉTODOS}

Foram realizados diversos testes utilizando a metodologia Box Test desenvolvida pela Suncoke Energy, de modo a identificar a real correlação entre o coque produzido dentro da caixa (Box Test) e o coque produzido no forno na qual a caixa era introduzida e submetida ao processo de coqueificação.

Uma vez conhecida a real correlação coque da caixa e coque do forno, uma série de experimentos foram desenvolvidos de modo a se desenvolver novas misturas. Primeiramente as misturas foram elaboradas via modelo matemático de previsão de qualidade de coque e posterirormente submetidas ao enfornamento via Box Test

\subsection{O PROCESSO HEAT RECOVERY DA SUNCOKE ENERGY}

Após o carregamento do forno, a coqueificação inicia-se ativada pelo calor remanescente no forno em função do ciclo anterior. Os voláteis liberados da massa de carvão e seus produtos de combustão são parcialmente queimados no interior da câmara sobre a camada de carvão. O ar primário para a combustão é introduzido através de válvulas de ar situadas nas portas do forno e dispostas acima do nível de carga. Os gases parcialmente queimados deixam o interior da câmara, através de dutos descendentes (downcomers) situados nas paredes em direção ao sistema de câmara de combustão (sole flues) situado abaixo da sola do forno. O fluxo de gás é resultado da tiragem induzida mantendo assim os fornos sob pressão negativa. $A$ combustão dos gases parcialmente queimados na câmara do forno prossegue no trajeto do gás através dos downcomers e é completada na região do sole flue. 
O tempo médio do ciclo de coqueificação é de 48 horas, período este em que é desenvolvida uma lenta taxa de coqueificação em temperaturas controladas. Os gases queimados deixam as câmaras de combustão por dutos ascendentes em direção a um túnel de captação comum a todos os fornos da bateria e em seguida são direcionadas para as caldeiras, nas quais há a troca de calor do gás com a água gerando vapor de alta pressão e alta temperatura. $O$ vapor produzido é enviado para as turbinas para a geração de energia elétrica, sendo que o gás após trocar de calor com a água é direcionado para a unidade de Dessulfuração, onde é devidamente tratado, antes de ser liberado para a atmosfera.

\subsection{BREVE DESCRIÇÃO DA CAIXA}

A caixa de teste consiste de uma armação metálica, rigidamente construída de modo a resistir às severas condições do processo de coqueificação, principalmente altas temperaturas, pressões geradas pelo processo de volatização dos carvões, impactos com o êmbolo desenfornador, além do choque térmico durante o processo de extinção a úmido do coque.

Construída em aço carbono, a caixa possui as dimensões adequadas para o desenvolvimento do testet. $O$ fundo e o topo da caixa são perfurados de modo a permitir a saída dos voláteis. Possui uma chapa divisora interna no sentido longitudinal para propiciar o teste simultâneo de dois materiais. A caixa possui dispositivos auxiliares para facilitar o transporte, bem como uma base devidamente desenhada para evitar avarias na soleira dos fornos de coqueificação. A figura 1 a seguir mostra um desenho da caixa.

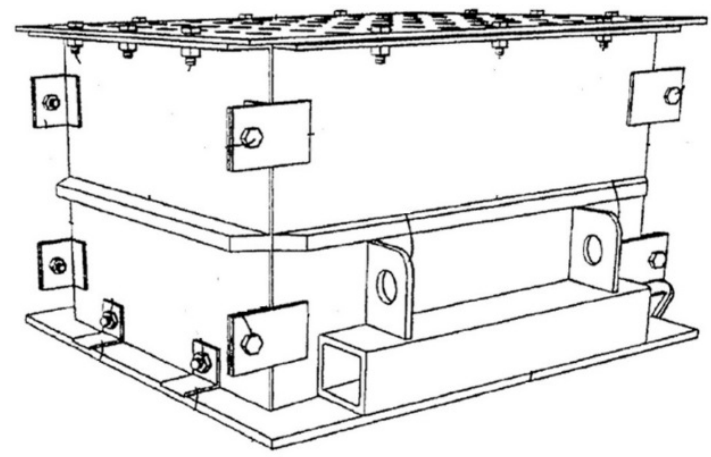

Figura 1. Caixa de teste desenvolvida pela SunCoke Energy.

\subsection{METODOLOGIA DO TESTE}

O teste foi conduzido em duas fases distintas, na primeira fase o intuito era avaliar o quão representativo era o coque produzido na caixa e o coque produzido no forno no qual a caixa era inserida. Os resultados mostraram uma excelente correlação, $\left(R^{2}\right.$ acima de 0,80 ) e validaram a metodologia para ser usada como ferramenta confiável para teste de novos carvões e novas misturas de carvões.

A segunda fase do teste, que atualmente já se incorporou à rotina da área de controle de qualidade da SunCoke Energy, trata-se da realização dos enfornamentos utilizando o Box Test das misturas previamente desenhadas via modelo de previsão, com foco em otimização de qualidade e redução de custo. 
Misturas altamente desafiadoras foram desenhadas, testadas e aprovadas via Box Test e propiciaram substanciais mudanças de perfis de blends e significativas reduções nos custos das misturas e do coque.

Filho [1] e Casagrande [2], em suas respectivas dissertações de mestrado, abordaram o tema Box Test com foco do uso desta técnica em coquerias by-product. A metodologia abordada pelos autores é praticamente a mesma; trata-se de uma caixa metálica reutilizada na qual é inserido o material a ser testado, sendo esta caixa posteriormente submetida a um forno piloto ou forno industrial. A grande diferença entre as caixas citadas por Filho [1] e Casagrande [2] e a metodologia desenvolvida pela SunCoke Energy é que, nesta última, a caixa foi cuidadosamente e exclusivamente construída para este fim, além de produzir uma quantidade de coque cerca de 20 vezes maior.

Na figura 2 é mostrada a caixa de teste citada por Filho [1] para a produção de coque a ser submetido a coqueificação em forno piloto.

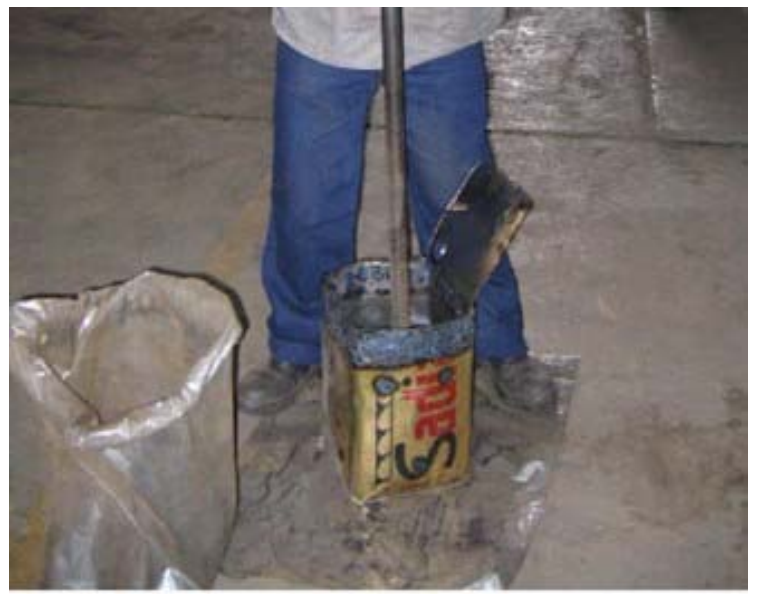

Figura 2. Caixa utilizada para box test, segundo Filho [1].

A figura 3 mostra a caixa de teste citada por Casagrande [2] para a produção de coque, após ser submetida ao processo de coqueificação em um forno industrial, tecnologia By-Product
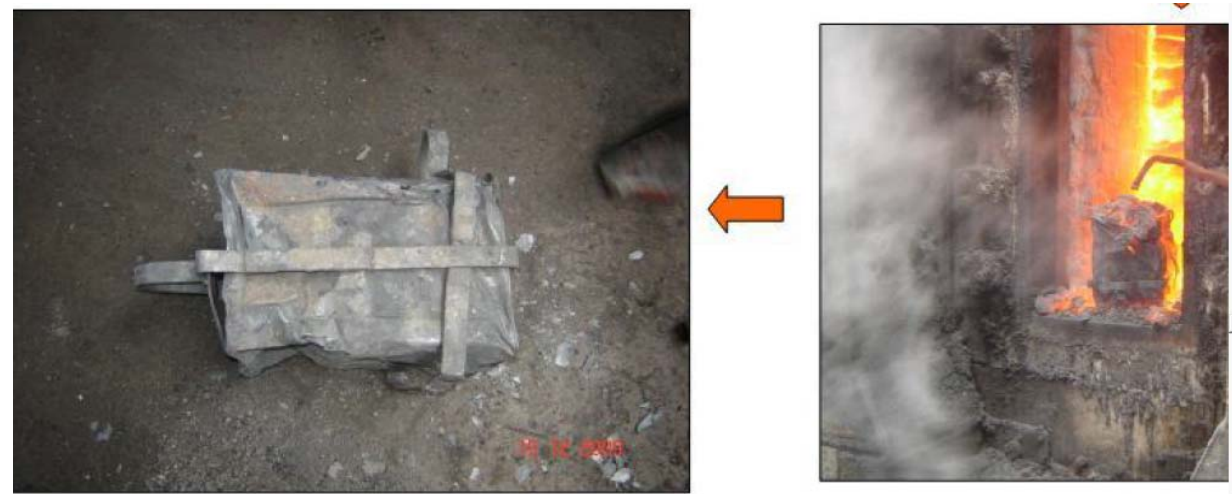

Figura 3. Caixa utilizada para box test, Casagrande [2].

\subsubsection{SEQUENCIAMENTO DAS ETAPAS PARA REALIZAÇÃO DO BOX TEST NA SUNCOKE ENERGY}

O teste possui uma sequência lógica que, obrigatoriamente, tem que ser respeitada de modo a atingir os resultados esperados. Esta sequência é subdividida em quatro etapas conforme descrito a seguir. 


\section{Etapa 1}

Elaboração das misturas via modelo matemático de previsão de qualidade de coque, objetivando avaliar uma mistura inusitada e que apresente algum desafio para redução de custo sem prejuízo à qualidade do coque.

\section{Etapa 2}

Preparação da mistura desenvolvida via modelo de previsão em laboratório. Esta é uma das fases mais importantes de todo o processo, visto que todos os carvões selecionados para a mistura a ser testada são manuseados em laboratório e submetidos à pesagem/dosagem, britagem, controle de umidade, controle de densidade e enchimento da caixa. Todas estas atividades são cuidadosamente realizadas de modo a se evitar desvios que possam comprometer todo o teste.

As figuras 4 e 5 mostram algumas etapas da preparação da caixa em laboratório.

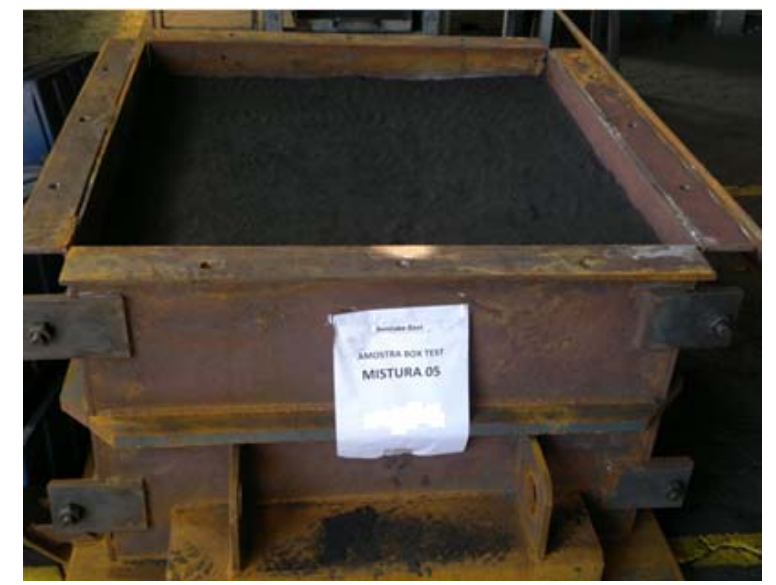

Figura 4. Preparação da caixa (enchimento lado 1).

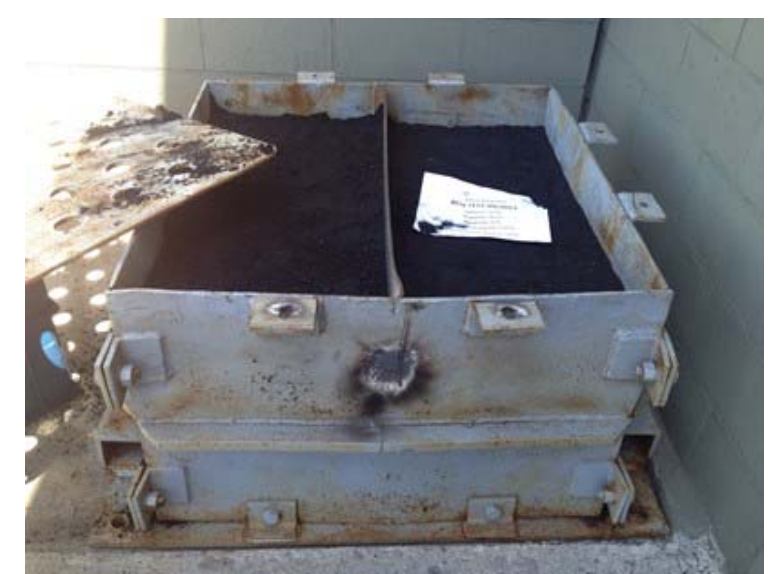

Figura 5. Preparação da caixa (enchimento lado 2).

\section{Etapa 3}

Enfornamento e retirada da caixa após extinção a úmido. Estes dois momentos caracterizam como sendo o início e término da exposição da caixa às condições reais do processo. Após a caixa ser inserida no forno, a mesma é totalmente coberta com a carga de mistura de carvão em uso na produção. Uma vez concluído o carregamento do forno e fechamento de portas, inicia-se 
o ciclo de coqueificação em que a mistura, ou carvão alvo de teste, serão submetidos.

A figura 6 elucida o sequenciamento anteriormente descrito.

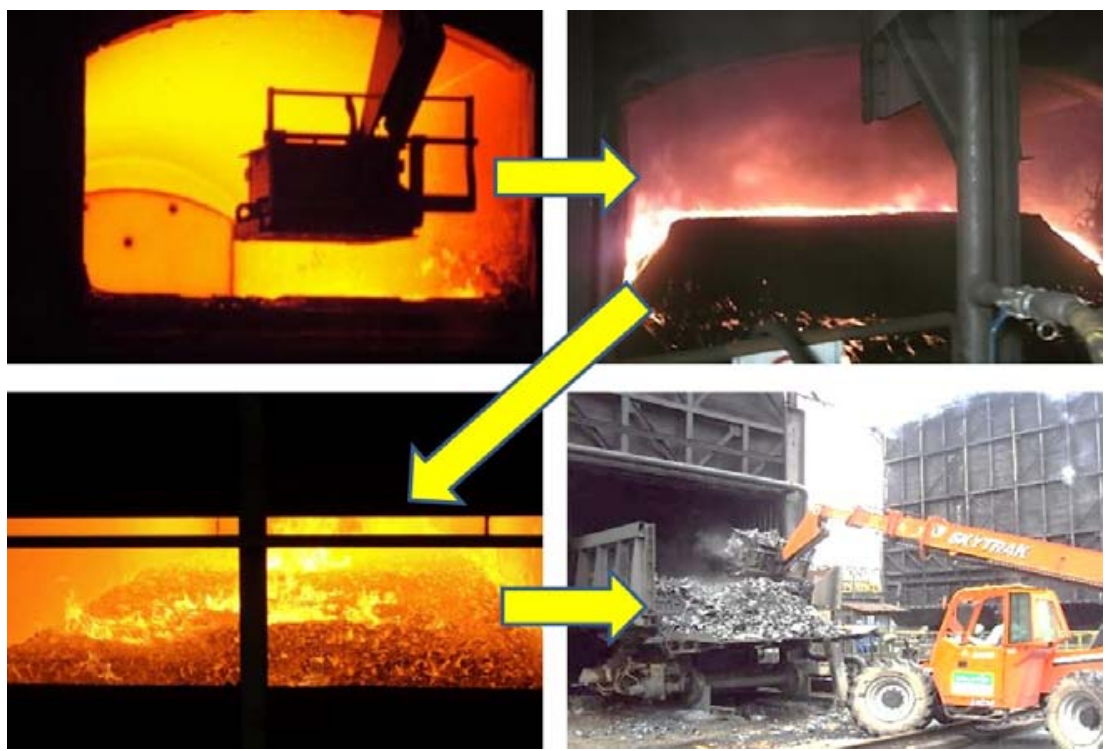

Figura 6. Sequenciamento das atividades de campo do Box Test da SunCoke Energy.

\section{Etapa 4}

Caracterização do coque em laboratório. Constitui a fase final do processo, no qual todas as análises relativas ao coque são realizadas. A gama de análises realizadas compreende: análise imediata (umidade, matéria volátil, cinza e enxofre); análise elementar (Carbono, Hidrogênio, Nitrogênio e Oxigênio); análise química da cinza; distribuição granulométrica, DI 150/15, CRI e CSR. Em se tratando de teste de um carvão novo ou uma mistura a ser testada, é nesta etapa que o laboratório de qualidade da SunCoke Energy emite um laudo técnico evidenciando o potencial de uso do material testado.

A figura 7 mostra um modelo de caixa de teste utilizado pela SunCoke Energy em que é possível identificar claramente o perfil de aquecimento em que esta foi submetida, revelando com nitidez a linha de coqueificação entre o coque de crown e sole flue.

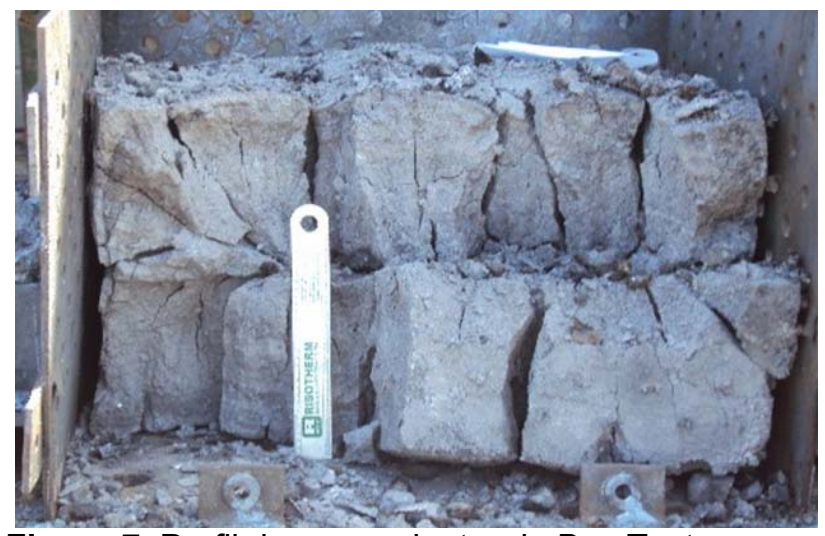

Figura 7. Perfil do coque dentro do Box Test. 


\section{RESULTADOS E DISCUSSÃO}

A metodologia de avaliação do potencial de coqueificação dos carvões e misturas aqui apresentada, tem se mostrado confiável o bastante para suportar substanciais modificações de perfis de misturas usadas na SunCoke Energy, que resultaram em significativa redução de custo das misturas e manutenção dos índices de qualidade do coque, principalmente CSR e DI 150/150.

Há de se ressaltar também que a utilização do Box Test desenvolvido pela SunCoke Energy, tem contribuído para a caracterização de diversos carvões eventualmente ofertados pelo mercado, porém ainda não usados na tecnologia heat recovery. Carvões da Indonésia, Rússia, África, Polônia e Colômbia já foram testados e devidamente avaliados quanto ao seu potencial de uso na tecnologia heat recovery. A aplicabilidade do teste não se resume apenas à caracterização de carvões, também pode ser utilizado para:

a) Teste de Rendimento coque carvão

b) Teste de Variação de densidade de carga

c) Teste de Novos combustíveis

d) Validação de misturas para coqueria by-product

e) Validação de modelo previsão de qualidade de coque

\subsection{RESULTADOS PRÁTICOS OBTIDOS}

O início da utilização do Box Test na SunCoke Energy foi em novembro de 2010, período em que os primeiros testes foram realizados na planta de Jewell, em Virginia, nos Estados Unidos. Também em 2010, em dezembro, iniciaram-se os primeiros testes com esta nova metodologia na planta da SunCoke Energy do Brasil, em Serra, ES.

O ano de 2011 foi um período de consolidação da metodologia, em que otimizações construtivas na caixa foram implementadas e também toda a parte laboratorial relativa ao Box Test foi devidamente adequada para promover robustez e confiabilidade nos resultados obtidos dos testes.

A partir de 2012, vários testes foram realizados de modo a desenvolver novos perfis de misturas, cujo objetivo era reduzir o custo destas misturas sem que houvessem flutuações na qualidade do coque.

A figura 8 mostra, além da evolução do perfil das misturas utilizadas na SunCoke Energy Brasil, a redução de custo das misturas considerando o ano de 2008 como base zero. Também são mostrados os períodos em que houve a utilização da metodologia Box Test como ferramenta suporte para validação de novas misturas.

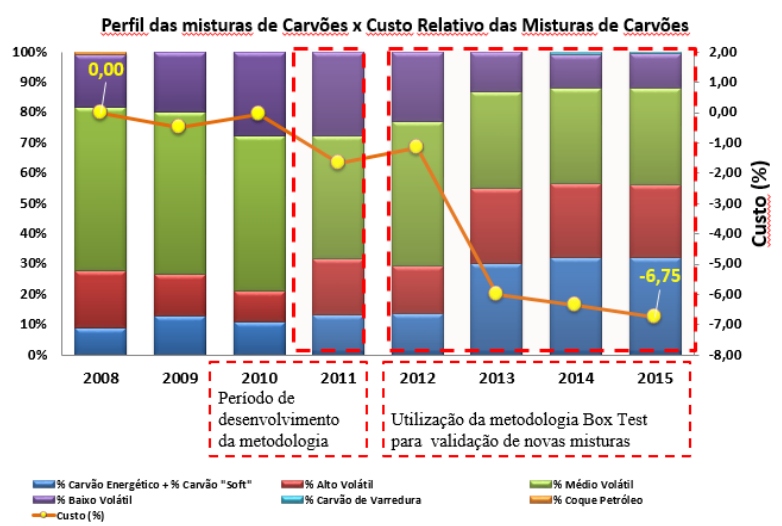

Figura 8. Evolução do perfil das misturas utilizadas na SunCoke Energy Brasil. 
Aliado à mudança de perfil das misturas e custo, os parâmetros de qualidade do coque também foram avaliados. Na figura 9 são mostradas a evolução do DI 150/15 do coque, bem como a redução de custo das misturas, no mesmo período em que houve as mudanças de perfil das misturas citadas anteriormente.

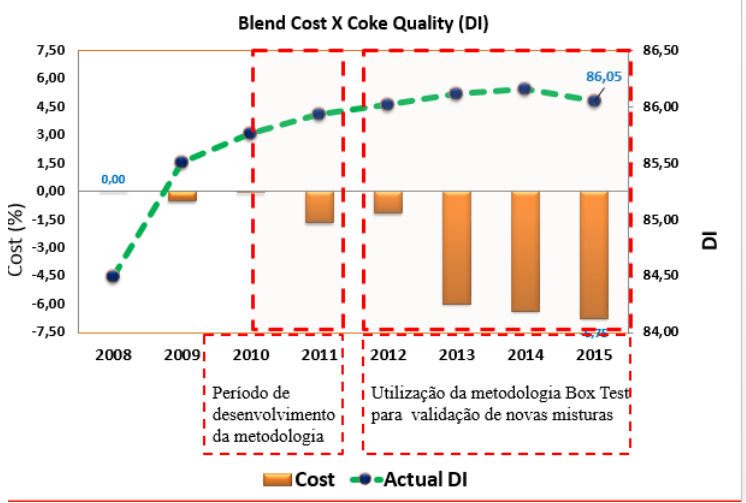

Figura 9. Evolução do DI 150/15 e redução de custo das misturas.

$\mathrm{Na}$ figura 10, é mostrado o comportamento do CSR do coque mediante as mudanças de perfil das misturas e também o fator custo.

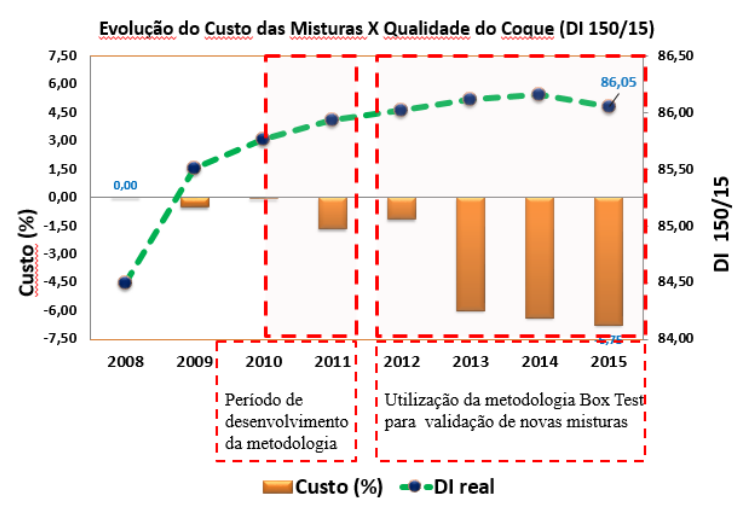

Figura 10. Evolução do CSR e redução de custo das misturas.

\section{CONCLUSÃO}

A metodologia aqui apresentada, constitui-se em uma importante e eficaz ferramenta para tomada de decisão quando se trata de definição de mudança de perfil de misturas, como também para certificar o potencial de coqueificação de determinados carvões eventualmente ofertados pelo mercado.

Por se tratar de um teste em que o material a ser testado é submetido às condições reais de processo, é conferida a esta metodologia, um alto grau de precisão quanto a previsibilidade de performance das misturas quando usadas em escala industrial.

Os dados aqui mostrados comprovam que uso da metodologia Box Test, desenvolvida pela SunCoke Energy, teve uma contribuição significativa para a otimização dos perfis de blends utilizados que resultaram em redução consistente do custo e preservação da qualidade do coque produzido. 


\section{REFERÊNCIAS}

1 FILHO, O.A.V. Estudo para o uso de matérias-primas nacionais em misturas de carvões para obtenção de coque com características requeridas em altos-fornos de alta produtividade. 2007. Dissertação de Mestrado (Mestrado em Engenharia de Materiais) de Minas). Universidade Federal de Minas Gerais. Belo Horizonte.

2 CASAGRANDE, C.M. Avaliação dos parâmetros de CRI e CSR do coque produzido em forno industrial, forno de soleira aquecida e Box Test. 2010. Dissertação de Mestrado (Mestrado em Engenharia Metalúrgica e de Minas). REDEMAT. Universidade Federal de Ouro Preto. Ouro Preto 